\title{
Natural history of nonfunctioning adrenal incidentalomas: a 10-year longitudinal follow-up study
}

\author{
Ana Podbregar ${ }^{1,2}$, Tomaž Kocjann ${ }^{1,3}$, Matej Rakuša ${ }^{1,3}$, Peter Popović ${ }^{1,4}$, Manca Garbajs ${ }^{1,4}$, Katja Goricar ${ }^{5}$, \\ Andrej Janez ${ }^{1,3}$ and Mojca Jensterle ${ }^{1,3}$ \\ ${ }^{1}$ Faculty of Medicine, University of Ljubljana, Ljubljana, Slovenia \\ ${ }^{2}$ University Rehabilitation Institute Republic of Slovenia, Ljubljana, Slovenia \\ ${ }^{3}$ Department of Endocrinology, Diabetes and Metabolic Disease, University Medical Center Ljubljana, Ljubljana, Slovenia \\ ${ }^{4}$ Clinical Institute of Radiology, University Medical Center Ljubljana, Ljubljana, Slovenia \\ ${ }^{5}$ Faculty of Medicine, Institute of Biochemistry, Pharmacogenetics Laboratory, University of Ljubljana, Ljubljana, Slovenia
}

Correspondence should be addressed to M Jensterle: mojcajensterle@yahoo.com

\begin{abstract}
Most data on the natural history of nonfunctioning adrenal incidentalomas (NFAI) are provided by follow-ups up to 5 years. We conducted a 10.5 (9.1-11.9)-year prospective follow-up study of NFAI in 67 participants (20 (29.9\%) males, 47 (70.1\%) females) of mean age $57.9(52.3-63.9)$ years and BMI $\left.27.42(24.07-30.56) \mathrm{kg} / \mathrm{m}^{2}\right)$. We also evaluated the associations between baseline BMI and changes of NFAls' characteristics at follow-up. Progression to mild autonomous cortisol excess (MACE) was observed in $15(22 \%)$ patients, with 14 of them having post overnight dexamethasone suppression test (ODST) cortisol between 50 and $138 \mathrm{nmol} / \mathrm{L}$ and only one $>138 \mathrm{nmol} / \mathrm{L}$. The progression rate was significantly higher in overweight and obese than in normal-weight subjects. Patients that developed MACE had a significantly higher baseline mean cortisol after $1 \mathrm{mg}$ ODST. Tumor enlargement $\geq 10 \mathrm{~mm}$ occurred in $8.9 \%$ of patients. In comparison with reports of shorter observational periods, we observed a higher growth rate $\geq 10 \mathrm{~mm}$ and higher progression rate from NFAI to MACE, particularly in overweight and obese subjects. All tumors had persistent radiological characteristics typical for adrenal adenoma. We concluded that the duration of the follow-up period is an important factor in characterizing the natural history of NFAI. Higher baseline BMI and higher baseline cortisol after ODST might predict the long-term likelihood of progression in hormonal activity. The magnitudes of observed progressions in growth or hormonal activity were clinically insignificant. Our long-term follow-up, therefore, clearly supports the general view that a long-term monitoring of patients with NFAI is not necessary.
\end{abstract}

\section{Key Words}

- adrenal incidentaloma

- body mass index

- benign nonfunctioning adrenal incidentaloma

- mild autonomous cortisol excess

- longitudinal studies

\section{Introduction}

Adrenal masses are mainly detected unexpectedly by an imaging study performed for reasons unrelated to any suspect of adrenal disease (1). Defined as adrenal incidentaloma (AI), such masses are found in about 5\% of the population with an age-dependent increase in incidence (2). Most AI are benign nonfunctioning adrenal incidentalomas (NFAI)s (3) that do not require surgery at the time of presentation (1). However, an increase in cardiometabolic risk during follow-up $(4,5)$, increases in NFAIs' size and development of mild autonomous cortisol excess (MACE) over time have also been reported for this clinical entity $(6,7,8,9)$.
Endocrine Connections (2021) 10, 637-645 
Currently, adequate long-term follow-up strategies of NFAIs after the initial assessment remain debatable. In contrast to previous guidelines from the National Institutes of Health and the American Association of Clinical Endocrinologists $(10,11)$, more recent European guidelines discourage repeated imaging and hormonal re-assessment (1). The largest retrospective cohort study including 1149 patients with the longest median follow-up duration of 4 year concluded that NFAIs with a size $<4 \mathrm{~cm}$ do not need to be followed-up with repeated CT measurements, as most remain stable in size for a long time (8). They also confirmed that NFAIs rarely evolve to become overt hormone-secreting tumors (8). Nevertheless, they advise an increased attention to the development of autonomous cortisol secretion and cardiometabolic comorbidities(8). Similarly, a 5-year prospective follow-up study in 56 patients indicated no clinically relevant tumor growth or a new subclinical hypercortisolism (12).

The role of obesity and insulin resistance in the development and natural history of NFAIs is unclear (13). Anabolic and mitogenic effects of insulin on the adrenal cortex support the potential existence of the bilateral relationship between obesity and AIs in preclinical models (13). However, it remains largely unaddressed whether patients with obesity more likely develop NFAIs and whether the radiological, hormonal changes of AI and development of cardiometabolic comorbidities are associated with baseline BMI $(14,15)$.

Based on these considerations, we aimed to determine the proportions of NFAI that increase in size and change their hormone production during long-term follow-up. We also assessed the prevalence of cardiometabolic comorbidities, osteoporosis and additional radiological findings during the observational period. We evaluated the potential associations between baseline BMI and radiological and hormonal changes of NFAI. We conducted a study with one of the longest mean follow-up periods and the first study that assessed the potential associations between baseline BMI and parameters determining the long-term natural history of NFAIs.

\section{Materials and methods}

\section{Study design}

We included 67 patients who had been hospitalized due to AI at the University Medical Centre Ljubljana from January 2007 to January 2011 and were characterized as NFAI. NFAI was confirmed when cortisol after $1 \mathrm{mg}$ overnight dexamethasone suppression test (ODST) was $<50 \mathrm{nmol} / \mathrm{L}$, no typical clinical signs of Cushing's syndrome were present and pheochromocytoma and primary aldosteronism were excluded (1). Radiologically, all included NFAIs had features of lipid-rich, benign adrenal adenoma defined by low unenhanced CT Hounsfield units (HU) of $\leq 10(16,17)$. Exclusion criteria were suspected metastasis, adrenal carcinoma, myelolipoma, adrenal hyperplasia, and patients on treatment with drugs that significantly interfere with measured variables, including oral hormonal contraceptives, glucocorticoids, mineralocorticoid antagonists and potassium-wasting diuretics or CYP3A4 inducers. In addition, we excluded all patients with symptomatic cholecystolithiasis, nephrolithiasis and pancreatitis. Subjects with hereditary syndromes associated with adrenal tumors were also excluded.

The study was registered at ClinicalTrails.gov, study identifier NCT04616703. It was conducted in accordance with the Declaration of Helsinki, approved by the National Ethical Committee with the reference number 0120$134 / 2019$. Consent has been obtained from each patient or subject after a full explanation of the purpose and nature of all procedures used.

\section{Study cohort}

Patients who had been diagnosed with NFAI at the University Medical Centre Ljubljana between January 2007 and January 2011 were invited for a follow-up visit. The medical records of all invited patients were reviewed by the authors to confirm the diagnosis of NFAI at baseline. The flowchart depicting the selection process of the 67 included patients with NFAI (20 (29.9\%) males, 47 (70.1\%) females) of median age at the time of initial diagnosis 57.9 (52.3-63.9) years) is presented in Fig. 1. Twenty patients had BMI $<25 \mathrm{~kg} / \mathrm{m}^{2}, 21 \mathrm{BMI} 25-30 \mathrm{~kg} / \mathrm{m}^{2}$ and 26 had $\mathrm{BMI}>30 \mathrm{~kg} / \mathrm{m}^{2}$ at the initial presentation. Fourteen patients had bilateral NFAI and 53 had unilateral NFAI. Mean follow-up was 10.5 (9.1-11.9) years. All follow-up visits were performed at the University Medical Centre Ljubljana from July 2019 to February 2020.

\section{Study protocol}

The following data were collected from the hospital documentation system as baseline characteristics at the time of diagnosis: patient gender, age at diagnosis, weight, height, size of NFAI, site of NFAI (left, right, or bilateral), blood pressure, heart rate, cortisol after $1 \mathrm{mg}$ ODST,

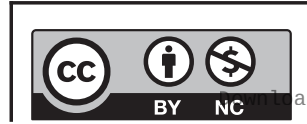

This work is licensed under a Creative Commons Attribution-NonCommercial 4.0 International License. ded from Bioscientifica.com at 04/26/2023 11:24:17AM 


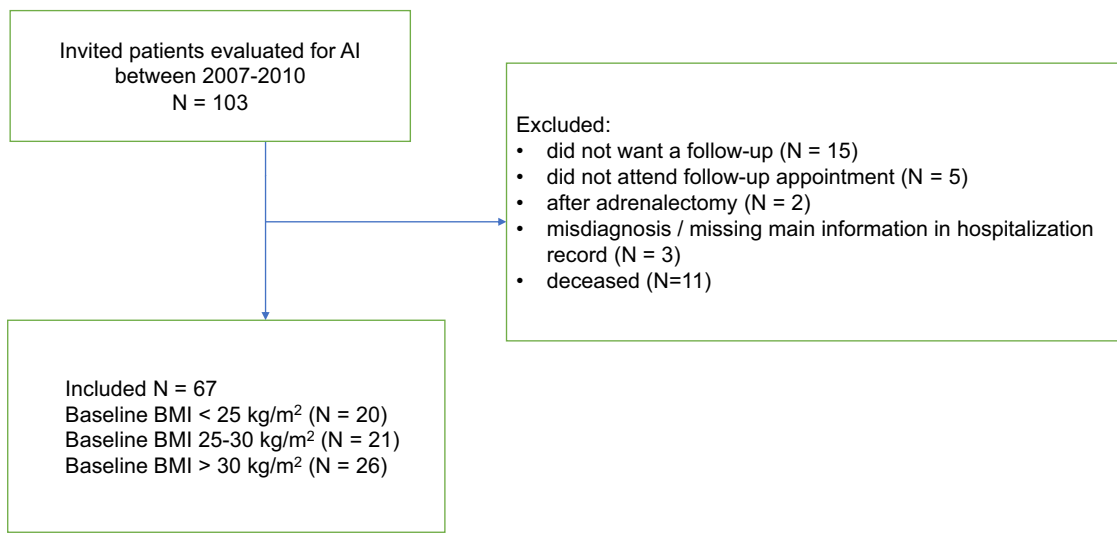

Figure 1

Flowchart of selection proccess. Al, adrenal incidentaloma; N, number of patients. fasting glucose, lipids (cholesterol, HDL, LDL, TAG). Data regarding the presence of comorbidities including hypertension, diabetes mellitus, osteoporosis, and hyperlipidemia at the time of diagnosis were collected from the hospital documentation system as binary variables (present, not present).

At the follow-up visit, we measured the patient's weight, blood pressure, heart rate, waist circumference and hip circumference. The blood was withdrawn for the measurement of fasting insulin, fasting glucose, lipids (cholesterol, HDL, LDL, TAG), and for cortisol after $1 \mathrm{mg}$ ODST the next morning. MACE was diagnosed when cortisol after ODST was $\geq 50 \mathrm{nmol} / \mathrm{L}$ (1). We performed CT scans to measure the size and growth rate of NFAI. Data on the presence of comorbidities including hypertension, diabetes mellitus, and hyperlipidemia at follow-up were collected in person, by checking the medical documentation and taking a history of comorbidities as binary variables (present, not present). In addition, at follow-up visit, we verified the accuracy of the data about the presence of comorbidities at baseline, collected from the hospital documentation system. All baseline data from the hospital documentation system matched with the data collected from patients in person at the follow-up visits. We did not collect data on disease severity, control and drug therapy at the baseline or the follow-up visit. Hypertension, diabetes mellitus and hyperlipidemia were diagnosed by primary care physicians or other specialists of internal medicine following the international guidelines. Osteoporosis was diagnosed at our center (18).

\section{Methods}

Anthropometric measurements were performed by trained nurses in the morning. BMI was calculated as the weight in kilograms divided by square of height in meters. Cortisol was determined using IMMULITE $^{\circledR} 2000$ Cortisol assay.
Intra-assay variations were $\leq 15 \%$ and inter-assay variations were $\leq 20 \%$ for the applied methods. Fasting glucose levels were determined using the standard glucose oxidase method (Beckman Coulter Glucose Analyzer, Beckman Coulter Inc., CA, USA). Lipids were determined using Advia 1800 , Siemen's analyzer. Intra-assay variations ranged from 1.6 to $6.3 \%$, and inter-assay variations ranged from 5.8 to $9.6 \%$ for the applied methods. Insulin was determined in heparinized plasma using a two-side chemiluminescent immunometric assay (Diagnostic Products Corp., Los Angeles, CA). The Homeostatic Model Assessment of Insulin Resistance $\left(\mathrm{HOMA}_{\mathrm{IR}}\right)$ score was calculated according to the following formula: fasting serum insulin $(\mu \mathrm{U} / \mathrm{mL}) \times$ fasting plasma glucose $(\mathrm{mmol} / \mathrm{L}) / 22.5$, patients treated with insulin were excluded. All patients underwent a thin slice CT scan (Siemens) according to the established adrenal protocol. Radiological evaluation included the largest transverse diameter of the lesion, laterality, native Hounsfield units (HU), absolute and relative percentage washout, and pathological changes on adjacent organs.

\section{Statistical analysis}

The results for continuous variables are presented as median and interquartile range and the results for categorical variables are presented as frequencies. Wilcoxon signed-rank test and McNemar test were used for the comparison of continuous and categorical variables for related samples, respectively. To compare the distribution of continuous variables between different groups, the nonparametric Mann-Whitney test or Kruskal-Wallis test was used. Pairwise comparisons with post hoc Bonferroni corrections were also used with Kruskal-Wallis test. Spearman's rho was used to assess the correlation between continuous variables, while Fisher's exact test was used to assess the association between categorical variables. $P$ values below 0.05 were considered statistically significant.

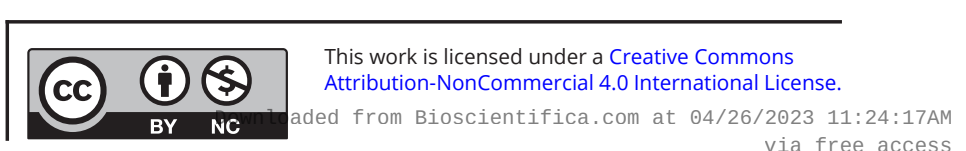


Statistical analysis was performed using IBM SPSS Statistics, version 21.0 (IBM Corporation).

\section{Results}

\section{Cohort characteristics at the baseline}

Baseline characteristics are presented in Table 1.

\section{The comparison of selected characteristics of patients at the baseline and follow-up}

After 10.5 (9.1-11.9) years of follow-up, cortisol after 1 mg ODST significantly increased, diastolic blood pressure decreased, fasting glucose significantly increased and HDL significantly increased, as outlined in Table 1.

At follow-up, we also observed significant increase in the prevalence of diabetes mellitus $(0.03 \%$ at baseline vs $17.9 \%$ at follow-up, $P=0.002)$, osteoporosis $(17.9 \%$ at baseline vs $26.9 \%$ at follow-up, $P=0.031$ ) and hypertension (52.2\% at baseline vs $64.2 \%$ at follow-up, $P=0.021$ ).

As stratified by baseline BMI, a group with baseline BMI $<25 \mathrm{~kg} / \mathrm{m}^{2}$ had higher cortisol after $1 \mathrm{mg}$ ODST $(P=0.014)$, higher body mass $(P=0.027)$, higher BMI $(P=0.024)$, higher fasting glucose $(P=0.004)$ and higher HDL $(P=0.021)$ after $10.5(9.1-11.9)$ years when compared to baseline characteristics. Group with BMI $25-30 \mathrm{~kg} / \mathrm{m}^{2}$ had higher follow-up cortisol after $1 \mathrm{mg}$ ODST $(P=0.002)$ and higher LDL $(P=0.041)$. Group with BMI $>30 \mathrm{~kg} / \mathrm{m}^{2}$ had higher follow-up cortisol after $1 \mathrm{mg}$ ODST $(P=0.001)$, higher diastolic blood pressure $(P=0.009)$ and higher HDL $(P=0.002)$ when compared to baseline characteristics.

The comparison of follow-up characteristics, when the groups were stratified by BMI at follow-up period, is presented in Table 2 . The groups differed in body mass, BMI, triglycerides, waist circumference, insulin and $\mathrm{HOMA}_{\mathrm{IR}}$.

Altogether, four patients were re-categorized from initial group with baseline BMI $<25 \mathrm{~kg} / \mathrm{m}^{2}$ to group with BMI $25-30 \mathrm{~kg} / \mathrm{m}^{2}$ at follow-up due to weight gain and one patient was re-categorized from the initial group with $\mathrm{BMI}>30 \mathrm{~kg} / \mathrm{m}^{2}$ to group with BMI $25-30 \mathrm{~kg} / \mathrm{m}^{2}$ due to weight loss. Others remained in the same category.

\section{Progression from NFAI to MACE}

As classified by inclusion criteria, all patients were diagnosed with NFAI at the time of presentation. During the follow-up period, 15 (22.4\%) out of 67 patients with NFAIs progressed to MACEs $(P<0.001)$, with 14 of them having post ODST cortisol between 50 and $138 \mathrm{nmol} / \mathrm{L}$ and one having cortisol after ODST > $138 \mathrm{nmol} / \mathrm{L}(167 \mathrm{nmol} / \mathrm{L})$. One out of $20(5 \%)$ progression was observed in patients with baseline $\mathrm{BMI}<25 \mathrm{~kg} / \mathrm{m}^{2}$, the patient had bilateral NFAI, in 7 out of 21 (33.3\%) patients in a group with BMI $25-30 \mathrm{~kg} / \mathrm{m}^{2}$, none of them had bilateral NFAI, and in 7 out of $26(26.7 \%)$ patients in a group with BMI $>30 \mathrm{~kg} / \mathrm{m}^{2}$, 3 of them had bilateral NFAI. The progression incidence was significantly higher in overweight and obese patients when compared to patients with baseline BMI $<25 \mathrm{~kg} / \mathrm{m}^{2}$ $\left(P=0.016\right.$ in both groups with BMI $\left.>25 \mathrm{~kg} / \mathrm{m}^{2}\right)$ (Fig. 2$)$. No patient developed overt Cushing's syndrome.

Table 1 Comparison of baseline and follow-up cohort characteristics.

\begin{tabular}{|c|c|c|c|}
\hline & $\begin{array}{c}\text { Baseline } \\
\text { median }(25-75 \%)\end{array}$ & $\begin{array}{c}\text { Follow-up } \\
\text { median }(25-75 \%)\end{array}$ & $\mathbf{P}$ \\
\hline Size of right-sided tumor (mm) & $25(15-28)[6]$ & 24.5 (14.75-30.25) & 0.227 \\
\hline Size of left-sided tumor (mm) & $20(14.5-28.5)[5]$ & $19(15-26)$ & 0.872 \\
\hline Cortisol after 1 mg ODST (nmol/L) & $28(27.6-32.8)^{a}$ & $38.5(30-48)^{a}$ & $<0.001 *$ \\
\hline Body mass (kg) & $73.25(65.98-87.53)$ & $76(67-87.5)$ & 0.213 \\
\hline $\operatorname{BMI}\left(\mathrm{kg} / \mathrm{m}^{2}\right)$ & $27.42(24.07-30.56)$ & $27.45(24.87-31.53)$ & 0.206 \\
\hline $\begin{array}{l}\text { Systolic blood } \\
\text { pressure (mmHg) }\end{array}$ & 135 (121-150) [4] & $140(124-150.25)[1]$ & 0.534 \\
\hline $\begin{array}{l}\text { Diastolic blood } \\
\text { pressure (mmHg) }\end{array}$ & $78(70-86)[4]$ & $76(68-81)[1]$ & $0.038 *$ \\
\hline Heart rate & $72.5(67-88.25)$ [17] & $72(67-82.5)[1]$ & 0.095 \\
\hline Fasting glucose (mmol/L) & $5.3(4.7-5.8)[2]$ & $5.4(5.1-6.1)$ & $0.006 *$ \\
\hline Total cholesterol (mmol/L) & $5.3(4.725-5.875)[19]$ & 5 (4.375-5.9) [1] & 0.896 \\
\hline $\mathrm{HDL}(\mathrm{mmol} / \mathrm{L})$ & $1.4(1.2-1.5)[19]$ & $1.4(1.2-1.8)[1]$ & $<0.001 *$ \\
\hline LDL (mmol/L) & $3.2(2.75-3.95)[22]$ & $2.8(2.2-3.6)[1]$ & 0.306 \\
\hline Triglycerides (mmol/L) & $1.4(1.025-1.975)[19]$ & $1.3(1-1.7)[1]$ & 0.265 \\
\hline
\end{tabular}

https://ec.bioscientifica.com

https://doi.org/10.1530/EC-21-0196 (c) 2021 The authors Published by Bioscientifica Ltd

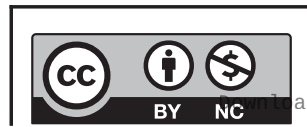

This work is licensed under a Creative Commons Attribution-NonCommercial 4.0 International License. ded from Bioscientifica.com at 04/26/2023 11:24:17AM 
Table 2 Patients characteristics at follow-up, stratified by BMI at follow-up.

\begin{tabular}{|c|c|c|c|}
\hline & $\begin{array}{c}\text { Baseline BMI }<\mathbf{2 5} \mathbf{~ k g / \mathbf { m } ^ { 2 }} \\
\text { (group 1) } \boldsymbol{n}=16 \mathbf{~ M e d i a n} \\
(25-75 \%)\end{array}$ & $\begin{array}{c}\text { Baseline BMI } \mathbf{2 5 - 3 0 ~} \mathbf{~ k g} / \mathbf{m}^{\mathbf{2}} \\
\text { (group 2) } \boldsymbol{n}=\mathbf{2 6} \text { Median } \\
(25-75 \%)\end{array}$ & $\begin{array}{c}\text { Baseline BMI }>\mathbf{3 0} \mathbf{~ k g} / \mathbf{m}^{\mathbf{2}} \\
\text { (group 3) } \boldsymbol{n}=\mathbf{2 5} \text { Median } \\
\text { (25-75\%) }\end{array}$ \\
\hline $\begin{array}{l}\text { Size of right-sided } \\
\text { tumor }(\mathrm{mm})\end{array}$ & $25(14-35)$ & 25 (19.75-30.75) & $19(13-30)$ \\
\hline $\begin{array}{l}\text { Size of left-sided } \\
\text { tumor }(\mathrm{mm})\end{array}$ & $17.5(12-27)$ & $19(15-27.25)$ & $18(15.75-26.25)$ \\
\hline $\begin{array}{l}\text { Cortisol after } 1 \text { mg ODST } \\
\text { (nmol/L) }\end{array}$ & $32(28.5-38.5)$ & $40(34-51)$ & $41(27.8-51.5)$ \\
\hline Body mass (kg) & $61.5(56.25-69.5)$ & $73.5(67.75-84)$ & 89 (79.08-99) \\
\hline $\mathrm{BMI}\left(\mathrm{kg} / \mathrm{m}^{2}\right)$ & 23.58 (21.41-24.44) & 27.09 (26.34-28.49) & 32.25 (31.44-35.93) \\
\hline $\begin{array}{l}\text { Systolic blood } \\
\text { pressure }(\mathrm{mmHg})\end{array}$ & $129.5(116.25-141)$ & $137.5(123.75-151)$ & 143.5 (125.5-153) [1] \\
\hline $\begin{array}{l}\text { Diastolic blood } \\
\text { pressure (mmHg) }\end{array}$ & $77(70.25-80)$ & 74.5 (66.75-83.5) & $76.5(68-83)$ \\
\hline Heart rate & 73 (64-89) & $74(69-83.25)$ & 70 (62-76) \\
\hline Fasting glucose (mmol/L) & $5.4(4.93-6.25)$ & $5.5(5.05-6.33)$ & $5.4(5.15-6.05)$ \\
\hline $\begin{array}{l}\text { Total cholesterol } \\
(\mathrm{mmol} / \mathrm{L})\end{array}$ & $5(4.23-5.75)$ & $4.7(4.1-6.1)[1]$ & $5.3(4.45-6.25)$ \\
\hline $\mathrm{HDL}(\mathrm{mmol} / \mathrm{L})$ & $1.6(1.33-2)$ & $1.4(1.15-1.8)[1]$ & $1.5(1.25-1.75)$ \\
\hline LDL (mmol/L) & $2.9(2.18-3.5)$ & $2.8(2-3.5)[1]$ & $2.8(2.5-4.05)$ \\
\hline Triglycerides (mmol/L) & $1.05(0.8-1.28)$ & $1.4(1-2.05)[1]$ & $1.4(1.1-1.85)$ \\
\hline Waist circumference (cm) & $88(73-90.5)$ [3] & $91(88.5-96.75)$ & $104(99-110.5)$ \\
\hline Insulin & $7.05(4.2-11.35)$ & $9.2(4.63-17.5)$ & $14.15(7-19.63)$ \\
\hline $\mathrm{HOMA}_{\mathrm{IR}}$ & $1.7(0.92-3.02)$ & $2.26(1.05-4.23)$ & $3.46(1.73-5.17)$ \\
\hline
\end{tabular}

$73.5(67.75-84)$

89 (79.08-99)

0.130

$<0.001$ *

Pairwise comparisons: 1

vs 2 : $0.016^{*}$

1 vs $3:<0.001 *$

2 vs 3: $0.001 *$

$<0.001$ *

Pairwise comparisons: 1

vs 2: 0.001 *

1 vs $3:<0.001 *$

2 vs $3:<0.001 *$

0.184

0.987

0.276

0.704

0.706

0.300

0.661

$0.012 *$

Pairwise comparisons: 1

vs 2 : $0.021^{*}$

1 vs 3: 0.026 *

$<0.001$ *

Pairwise comparisons: 1

vs 3: $<0.001$ *

2 vs $3:<0.001 *$

0.034 *

Pairwise comparisons: 1 vs 3: $0.033^{*}$

$0.033^{*}$

Pairwise comparisons: 1 vs 3: 0.031 *

P-values and pairwise comparisons with post hoc Bonferroni corrections were calculated using Kruskal-Wallis test.

*Asterisks were used to indicate significant figures (probability).

$\mathrm{HDL}$, high-density lipoprotein; $\mathrm{HOMA}_{\mathrm{IR}}$, homeostatic model assessment of insulin resistance; LDL, low-density lipoprotein; ODST, 1 mg overnight

dexamethasone suppression test.

\section{Comparison of baseline and follow-up characteristics of NFAI that progress to MACE and NFAl that did not developed MACE}

Patients with NFAI that developed MACE by the follow-up visit, differed from patients without progression to MACE in higher cortisol after $1 \mathrm{mg}$ ODST at baseline (32.6 (28.7-42.5) nmol/L vs 28 (27.6-31.7) nmol/L; $P=0.015)$ and at follow-up (64 (52-85) nmol/L vs 34.0 (27.6-40) nmol/L;
$P<0.001)$, higher heart rate (84 (71.25-102.25) beats/min vs 70.5 (64.75-84.5) beats/min; $P=0.048)$ and higher fasting glucose at baseline $(5.7(5.3-6.4) \mathrm{mmol} / \mathrm{L}$ vs 5.1 (4.6-5.6) $\mathrm{mmol} / \mathrm{L} ; P=0.006)$ and at follow-up (6 (5.3-6.9) $\mathrm{mmol} / \mathrm{L}$ compared to $5.4(5.05-5.95) \mathrm{mmol} / \mathrm{L} ; P=0.036)$.

There were no statistical differences in prevalence of hypertension, hyperlipidemia, diabetes mellitus and osteoporosis between NFAI and MACE $(P>0.05)$ at follow-up period. https://ec.bioscientifica.com

https://doi.org/10.1530/EC-21-0196 (c) 2021 The authors Published by Bioscientifica Ltd

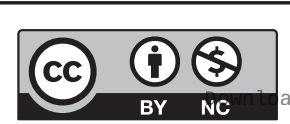

This work is licensed under a Creative Commons Attribution-NonCommercial 4.0 International License. ded from Bioscientifica.com at 04/26/2023 11:24:17AM via free access 


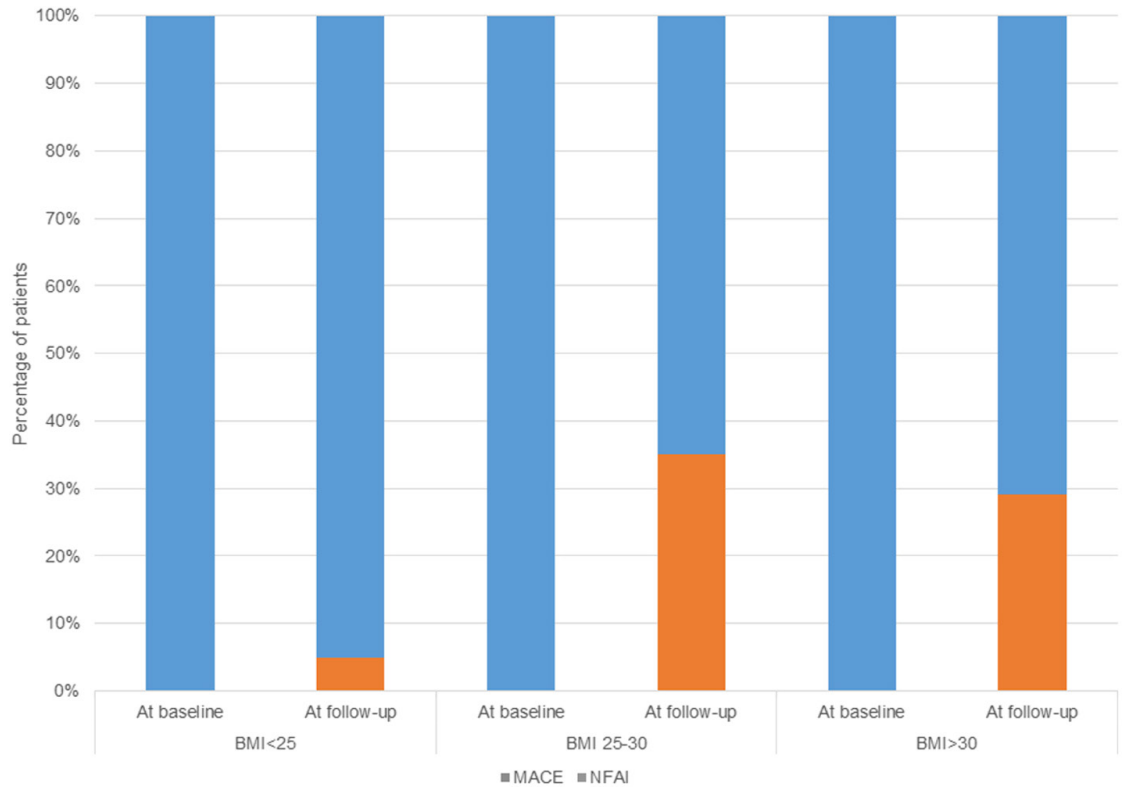

\section{Figure 2}

Progression from NFAI to MACE stratified by BMI. MACE, adenomas causing mild autonomous cortisol excess; NFAl, benign nonfunctioning adrenal incidentaloma.

\section{Change in NFAls size}

Maximal mean tumor growth was 0 ( -2 to 5$) \mathrm{mm}$ over 10.5 (9.1-11.9) years. Enlargement of NFAI was observed in 38 patients.

Tumor enlargement ( $\geq 10 \mathrm{~mm}$ ) occurred in three patients with left-sided and three patients with right-sided NFAI, all together in six patients (8.9\%). None of those six patients had bilateral NFAI. At the follow-up, all tumors still had radiological characteristics typical for adrenal adenoma. None developed CT characteristics typical for adrenal cancer.

We observed no significant correlation between tumor growth and baseline size or BMI. Tumors that were initially smaller (less than $25 \mathrm{~mm}$ ) did not have greater growth potential than larger ones (those larger than 25 $\mathrm{mm})$. There was positive correlation between maximal tumor diameter at follow-up and cortisol after $1 \mathrm{mg}$ ODST $(\rho=0.412, P=0.002)$ at follow-up.

\section{Other findings on CT at follow-up}

We collected data about additional CT findings at the follow-up CT scan. At the follow-up, 37.9\% of patients had additional CT changes in kidneys, $21.2 \%$ in gastrointestinal tract, $18.2 \%$ in liver region, and $10.4 \%$ in pancreas, mostly cysts. In the liver region, we observed cystic changes $(n=7$ in BMI $<25 \mathrm{~kg} / \mathrm{m}^{2}, n=5$ in BMI $25-30 \mathrm{~kg} / \mathrm{m}^{2}$ and $n=1$ in $\left.\mathrm{BMI}<30 \mathrm{~kg} / \mathrm{m}^{2}\right)$, steatosis $\left(\mathrm{n}=1\right.$ in BMI $<25 \mathrm{~kg} / \mathrm{m}^{2}, n=2$ in BMI $25-30 \mathrm{~kg} / \mathrm{m}^{2}$ and $n=2$ in BMI $<30 \mathrm{~kg} / \mathrm{m}^{2}$ ), some patients underwent cholecystectomy $(n=2$ in $\mathrm{BMI}<25$ $\mathrm{kg} / \mathrm{m}^{2}, n=5$ in BMI $25-30 \mathrm{~kg} / \mathrm{m}^{2}$ and $n=1$ in BMI $<30$ $\mathrm{kg} / \mathrm{m}^{2}$ ). In the kidney region, we observed cystic changes $\left(n=4\right.$ in BMI $<25 \mathrm{~kg} / \mathrm{m}^{2}, n=7$ in BMI $25-30 \mathrm{~kg} / \mathrm{m}^{2}$ and $n=4 \mathrm{in} \mathrm{BMI}<30 \mathrm{~kg} / \mathrm{m}^{2}$ ) and kidney stones ( $n=1$ in BMI 25-30 $\mathrm{kg} / \mathrm{m}^{2}$ ). In the gastrointestinal tract, we observed diverticulitis $\left(n=4\right.$ in BMI $<25 \mathrm{~kg} / \mathrm{m}^{2}, n=4$ in BMI $25-30$ $\mathrm{kg} / \mathrm{m}^{2}$ and $n=3$ in BMI $<30 \mathrm{~kg} / \mathrm{m}^{2}$ ). In pancreas, we observed cystic changes $\left(n=1\right.$ in BMI $<25 \mathrm{~kg} / \mathrm{m}^{2}, n=1$ in $\left.\mathrm{BMI}<30 \mathrm{~kg} / \mathrm{m}^{2}\right)$ and atrophy $\left(n=3\right.$ in BMI $\left.25-30 \mathrm{~kg} / \mathrm{m}^{2}\right)$. Panniculitis was observed in one patient with BMI $<25 \mathrm{~kg} / \mathrm{m}^{2}$ and one with BMI $25-30 \mathrm{~kg} / \mathrm{m}^{2}$. Prostate enlargement was observed in males $(n=1$ in $\mathrm{BMI}<25$ $\mathrm{kg} / \mathrm{m}^{2}, n=5$ in BMI $25-30 \mathrm{~kg} / \mathrm{m}^{2}$ and $n=1$ in BMI $<30$ $\left.\mathrm{kg} / \mathrm{m}^{2}\right)$, while a myoma of the uterus $(n=1$ in BMI $25-30 \mathrm{~kg} / \mathrm{m}^{2}$ ) and cysts of the ovaries ( $n=1$ in BMI $>30$ $\mathrm{kg} / \mathrm{m}^{2}$ ) were found in females. We observed atherosclerotic changes and dilatation of aorta $\left(n=1\right.$ in BMI $<25 \mathrm{~kg} / \mathrm{m}^{2}$, $n=3$ in BMI $25-30 \mathrm{~kg} / \mathrm{m}^{2}$ and $n=2$ in BMI $\left.<30 \mathrm{~kg} / \mathrm{m}^{2}\right)$. In BMI group $25-30 \mathrm{~kg} / \mathrm{m}^{2}$, we observed one patient with lung nodules, one with Bochdalek's hernia and one with fracture of eleventh thoracic vertebra. In one patient with $\mathrm{BMI}>30 \mathrm{~kg} / \mathrm{m}^{2}$, hiatal hernia was observed.

Notably, in three patients with BMI > $30 \mathrm{~kg} / \mathrm{m}^{2}$ referrals to further diagnostic procedures were needed to rule out malignant disease. In one patient, enlarged lymph nodes were observed, in one possible metastatic changes in s.c. tissue and in one possible metastatic renal carcinoma. 


\section{Discussion}

The majority of NFAI did not change in size and hormonal production during the 10.5-(9.1-11.9)year follow-up period. Progression from NFAI to MACE was observed in 15 (22\%) patients, with 14 of them having post ODST cortisol between 50 and138 nmol/L and one having post ODST cortisol $>138 \mathrm{nmol} / \mathrm{L}$. Four patients that progressed to MACE had bilaterally NFAI, one with BMI $<25 \mathrm{~kg} / \mathrm{m}^{2}$ and three with BMI $>30 \mathrm{~kg} / \mathrm{m}^{2}$. The progression rate to MACE was significantly higher in overweight and obese patients as compared to the group with normal weight at the time of presentation. Enlargement of NFAI was observed in 56.7\% of patients while clinically significant tumor enlargement $\geq 10 \mathrm{~mm}$ occurred in six patients. All tumors had persistent radiological characteristics that were typical for adrenal adenoma.

As opposed to our results, a recent systemic review and meta analysis (2) reported that only $4.3 \%$ (CI, $3.4 \%$ to $5.3 \%$ ) of patients with NFAI developed MACE during a mean follow-up of 50.3 months. We observed a significantly higher progression rate of $22 \%$ during 126.1 (108.9-142.3) months implying that the duration of follow-up is an important factor in the characterization of the natural history of NFAI. Importantly, the progression rate in overweight and obese patients was significantly higher than in normal-weight subjects.

The potential primary role of obesity and insulin resistance in the development of MACE in pre-existent NFAIs needs to be elucidated. Translational studies evaluating the molecular phenotype of AI related to insulin, IGF1 and MAPK signaling pathways might provide further insights into the bidirectional relationship between obesity and NFAIs (13). Moreover, interventional studies with insulin sensitizers and anti-obesity modalities in overweight/obese patients with NFAI should address the potential impact on the natural history of NFAI. Consistent with previous reports of shorter follow-up (19, 20), no patients from our cohort developed overt Cushing syndrome even after 10-year-mean follow-up.

The mean cortisol after $1 \mathrm{mg}$ ODST in patients with NFAI that developed MACE was $>30$ as compared to $<30$ $\mathrm{nmol} / \mathrm{L}$ in those that remained classified as NFAI at 10-year follow-up period. The baseline post ODST cortisol $>30$ $\mathrm{nmol} / \mathrm{L}$ should, therefore, be further assessed as a potential predictor of activity progression over long-term follow-up. The same range of post ODST cortisol between 30 and 50 $\mathrm{nmol} / \mathrm{L}$ has been previously related to higher prevalence of diabetes mellitus (5) and the authors challenged the accepted cut-off criteria of $>50 \mathrm{nmol} / \mathrm{L}$ used to currently classify adrenal incidentaloma as NFAI (1). Both findings emphasize the importance of understanding that the hormonal activity of $\mathrm{AI}$ is a continuum, particularly in the evaluation of the contribution of AI to cardiometabolic risk (5).

In line with the continuous relationship between the secretory activity of $\mathrm{AI}$ and its contribution to cardiometabolic risk, we observed no difference in the prevalence of observed comorbidities between the patients with persistent NFAI and those that had progressed to MACE at 10-year follow-up. However, our study was not designed for conclusive observations on the prevalence of comorbidities.

Notably, the follow-up duration seems to be an important factor in characterizing the natural history of growth rate in NFAI. Over a mean follow-up of 41.9 months, an increase of at least $10 \mathrm{~mm}$ was reported in only $1.2 \%$ of NFAI (2). Only $0.9 \%$ of adenomas grew by at least $10 \mathrm{~mm}$ when the mean follow-up was shorter than 24 months, compared with $2.9 \%$ of adrenal tumors followed for at least 24 months (2). However, in a recent study, $11.7 \%$ of the patients had an increase $\geq 10 \mathrm{~mm}$ at 24 month follow-up (21) that was similar to our cohort, where tumor enlargement $(\geq 10 \mathrm{~mm})$ occurred in $8.9 \%$ of patients. Some previous observations proposed that adenomas with a baseline size of at least $25 \mathrm{~mm}$ were less likely to grow than smaller adenomas $(<25 \mathrm{~mm})$ suggesting that patients with larger tumors were involved later in their course of natural history (2); however, we did not observe such differences.

We observed a high incidence of concomitant CT findings in this population, in 3 out of 26 patients from the obese group the incidental findings were suspicious for malignant disease. Based on the numerous data that the majority of NFAI do not change in size and that do not progress to adrenocortical carcinoma, 2016 ESE-ENSAT European guidelines for AIs discourage repeated imaging re-assessment (1) because of the substantial health economic burden and increased radiation exposure from potentially unnecessary repeated evaluations (2). The clinical importance of concomitant CT findings during long-term observational period, in particular in the obese group, remains unclear and should be addressed in future research.

The main limitation of our study is the limited sample size. However, the sample size was comparable to another single-center cohort study addressing the natural course of AI of shorter, 5-year follow-up (12). Secondly, aging of the cohort likely acts as an important confounder affecting the development of numerous concomitant CT findings and cardiometabolic comorbidities. Background

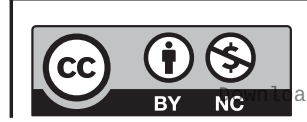

This work is licensed under a Creative Commons Attribution-NonCommercial 4.0 International License. ded from Bioscientifica.com at 04/26/2023 11:24:17AM 
general population as a control group would be needed for more conclusive results on the prevalence of diabetes, hypertension and osteoporosis, as well as additional CT findings. However, the main outcome of our study is defined as a long-term natural history of NFAI was not affected by the lack of background population.

The main strength of our study is a length of 10.5year follow-up that was performed in a single tertiary university center. Dedicated interdisciplinary team using a standardized unique protocol performed baseline and follow-up assessments. Furthermore, this is the first report suggesting that baseline higher BMI might have an impact on the progression from NFAI to MACE, which is in line with the recent concept of the potential existence of the bilateral relationship between obesity and AIs in preclinical models (13).

Based on our results, we concluded that the duration of follow-up period is an important factor in characterizing the natural history of NFAI. In comparison with previous reports of shorter duration, we mostly observed a higher growth rate $\geq 10 \mathrm{~mm}$ and a higher progression rate from NFAI to MACE, particularly demonstrated in overweight and obese subjects. However, the magnitudes of observed progressions in growth or hormonal activity were clinically insignificant. Our long-term follow-up, therefore, clearly supports the general view that monitoring patients with NFAI is not necessary (1). In future studies, we suggest the evaluation of the primary role of baseline BMI and IR in the development of measurable hormonal activity in NFAI.

\section{Declaration of interest}

The authors declare that there is no conflict of interest that could be perceived as prejudicing the impartiality of the research reported.

\section{Funding}

This research did not receive any specific grant from any funding agency in the public, commercial or not-for profit sector.

\section{Author contribution statement}

$\mathrm{M}$ J, $\mathrm{T} K$ and $\mathrm{A}$ J have designed the study. A P recruited the patients and collected the data. A P and M J drafted the manuscript. M J, M R and T K managed the patients. P P and M G performed CT assessment. M J was a consultant and research supervisor. $\mathrm{G}$ K performed the statistical analysis. All authors were involved in the critical review of the manuscript. All authors have given final approval of the version to be published.

\section{Acknowledgements}

The authors thank all the physicians from the Department of Endocrinology, Diabetes and Metabolic Diseases, University Medical
Centre Ljubljana, Ljubljana, Slovenia for the management of patients with adrenal incidentaloma.

\section{References}

1 Fassnacht M, Arlt W, Bancos I, Dralle H, Newell-Price J, Sahdev A, Tabarin A, Terzolo M, Tsagarakis S \& Dekkers OM. Management of adrenal incidentalomas: european society of endocrinology clinical practice guideline in collaboration with the european network for the study of adrenal tumors. European Journal of Endocrinology $2016 \mathbf{1 7 5}$ G1-G34. (https://doi.org/10.1530/EJE-16-0467)

2 Elhassan YS, Alahdab F, Prete A, Delivanis DA, Khanna A, Prokop L, Murad MH, O'Reilly MW, Arlt W \& Bancos I. Natural history of adrenal incidentalomas with and without mild autonomous cortisol excess: a systematic review and meta-analysis. Annals of Internal Medicine 2019 171 107-116. (https://doi.org/10.7326/M18-3630)

3 Mantero F, Terzolo M, Arnaldi G, Osella G, Masini AM, Ali A, Giovagnetti M, Opocher G \& Angeli A. A survey on adrenal incidentaloma in italy. Study group on adrenal tumors of the italian society of endocrinology. Journal of Clinical Endocrinology and Metabolism 200085 637-644. (https://doi.org/10.1210/jcem.85.2.6372)

4 Ribeiro Cavalari EM, de Paula MP, Arruda M, Carraro N, Martins A, de Souza K, Coelho MC, de Oliveira E Silva de Morais NA, Moraes AB \& Vieira Neto L. Nonfunctioning adrenal incidentaloma: a novel predictive factor for metabolic syndrome. Clinical Endocrinology 2018 89 586-595. (https://doi.org/10.1111/cen.13822)

5 Lopez D, Luque-Fernandez MA, Steele A, Adler GK, Turchin A \& Vaidya A. "Nonfunctional" adrenal tumors and the risk for incident diabetes and cardiovascular outcomes: a cohort study. Annals of Internal Medicine 2016165 533-542. (https://doi.org/10.7326/M160547)

6 Barzon L, Scaroni C, Sonino N, Fallo F, Paoletta A \& Boscaro M. Risk factors and long-term follow-up of adrenal incidentalomas. Journal of Clinical Endocrinology and Metabolism 199984 520-526. (https://doi. org/10.1210/jcem.84.2.5444)

7 Vassilatou E, Vryonidou A, Michalopoulou S, Manolis J, Caratzas J, Phenekos C \& Tzavara I. Hormonal activity of adrenal incidentalomas: results from a long-term follow-up study. Clinical Endocrinology 2009 70 674-679. (https://doi.org/10.1111/j.1365-2265.2008.03492.x)

8 Hong AR, Kim JH, Park KS, Kim KY, Lee JH, Kong SH, Lee SY, Shin CS, Kim SW \& Kim SY. Optimal follow-up strategies for adrenal incidentalomas: reappraisal of the 2016 ESE-ENSAT guidelines in real clinical practice. European Journal of Endocrinology 2017177 475-483. (https://doi.org/10.1530/EJE-17-0372)

9 Papanastasiou L, Alexandraki KI, Androulakis II, Fountoulakis S, Kounadi T, Markou A, Tsiavos V, Samara C, Papaioannou TG, Piaditis G, et al. Concomitant alterations of metabolic parameters, cardiovascular risk factors and altered cortisol secretion in patients with adrenal incidentalomas during prolonged follow-up. Clinical Endocrinology 201786 488-498. (https://doi.org/10.1111/cen.13294)

$10 \mathrm{NIH}$. State-of-the-science statement on management of the clinically inapparent adrenal mass ("incidentaloma"). NIH Consens State Sci Statements 200219 1-25.

11 Zeiger MA, Thompson GB, Duh QY, Hamrahian AH, Angelos P, Elaraj D, Fishman E, Kharlip J, American Association of Clinical Endocrinologists \& American Association of Endocrine Surgeons. The American Association of Clinical Endocrinologists and American Association of Endocrine Surgeons medical guidelines for the management of adrenal incidentalomas. Endocrine Practice 200915 1-20. (https://doi.org/10.4158/EP.15.S1.1)

12 Schalin-Jantti C, Raade M, Hamalainen E \& Sane T. A 5-year prospective follow-up study of lipid-rich adrenal incidentalomas: no tumor growth or development of hormonal hypersecretion. Endocrinology and Metabolism 201530 481-487. (https://doi. org/10.3803/EnM.2015.30.4.481) 
13 Sydney GI, Ioakim KJ \& Paschou SA. Insulin resistance and adrenal incidentalomas: a bidirectional relationship. Maturitas 2019121 1-6. (https://doi.org/10.1016/j.maturitas.2018.12.002)

14 Podbregar A, Janez A, Goricar K \& Jensterle M. The prevalence and characteristics of non-functioning and autonomous cortisol secreting adrenal incidentaloma after patients' stratification by body mass index and age. BMC Endocrine Disorders 202020 118. (https://doi. org/10.1186/s12902-020-00599-0)

15 Morelli V, Masserini B, Salcuni AS, Eller-Vainicher C, Savoca C, Viti R, Coletti F, Guglielmi G, Battista C, Iorio L, et al. Subclinical hypercortisolism: correlation between biochemical diagnostic criteria and clinical aspects. Clinical Endocrinology 201073 161-166. (https:// doi.org/10.1111/j.1365-2265.2010.03794.x)

16 Boland GW, Lee MJ, Gazelle GS, Halpern EF, McNicholas MM \& Mueller PR. Characterization of adrenal masses using unenhanced CT: an analysis of the CT literature. AJR: American Journal of Roentgenology 1998171 201-204. (https://doi.org/10.2214/ ajr.171.1.9648789)

17 Caoili EM, Korobkin M, Francis IR, Cohan RH \& Dunnick NR. Delayed enhanced CT of lipid-poor adrenal adenomas. AJR: American Journal of Roentgenology 2000175 1411-1415. (https://doi.org/10.2214/ ajr.175.5.1751411)

18 Kanis JA, Cooper C, Rizzoli R, Reginster JY \& Scientific Advisory Board of the European Society for C, Economic Aspects of O. European guidance for the diagnosis and management of osteoporosis in postmenopausal women. Osteoporosis International 201930 3-44. (https://doi.org/10.1007/s00198-018-4704-5)

19 Loh HH, Yee A, Loh HS, Sukor N \& Kamaruddin NA. The natural progression and outcomes of adrenal incidentaloma: a systematic review and meta-analysis. Minerva Endocrinologica 201742 77-87. (https://doi.org/10.23736/S0391-1977.16.02394-4)

20 Cawood TJ, Hunt PJ, O'Shea D, Cole D \& Soule S. Recommended evaluation of adrenal incidentalomas is costly, has high false-positive rates and confers a risk of fatal cancer that is similar to the risk of the adrenal lesion becoming malignant; time for a rethink? European Journal of Endocrinology 2009161 513-527. (https://doi.org/10.1530/EJE-09-0234)

21 Yilmaz N, Avsar E, Tazegul G, Sari R, Altunbas H \& Balci MK. Clinical characteristics and follow-up results of adrenal incidentaloma. Experimental and Clinical Endocrinology and Diabetes 2021129 349-356. (https://doi.org/10.1055/a-1079-4915)

Received in final form 21 April 2021

Accepted 19 May 2021

Accepted Manuscript published online 19 May 2021
This work is licensed under a Creative Commons Attribution-NonCommercial 4.0 International License. ded from Bioscientifica.com at 04/26/2023 11:24:17AM 